\title{
Risk Management Practices and SMEs: An empirical study on Turkish SMEs
}

\author{
Farzaneh Soleimani Zoghi
}

\begin{abstract}
SMEs have a crucial role in the domestic economic growth. SMEs are organizations with higher adoptability and flexibility compare to large enterprise. However they are very vulnerable to risks due to the lack of established structure and limited resources. So risk management practices and strategies play a significant role in SMEs success and growth. Risk management involves identifying risks and predicting how probable they are and how serious they might become. Dealing with identified risks and deciding on what to do with them is a key issue in risk management process. The present study attempts to investigate the current state of risk management in Turkish SMEs more comprehensively. The research topic is to determine the dependency of industrial sector of SMEs and their risk management approach. The sample was developed from the data of 2000 Turkish SMEs. From 200 total responses 192 of them has been found as qualified response for statistical analysis. Data have been gathered by using categorical and multiple response questions with nominal and ordinal scales. The results of cross-tabulation and Chi- square test have revealed evidence of relationship and association between variables in many cases.
\end{abstract}

Index Terms-Risk, risk management (RM) process, SMEs (small to medium-sized enterprises).

\section{INTRODUCTION}

Because of the increasing pace of technological development and globalization of the marketplace, business environment become more and more risky and challenging for companies. Knowing how to identify, analyze and response to different types of risks in today's business environment are essential for survival. SMEs (Small to Medium-Sized Enterprises), due to their limited resources and structural features, are more influenced by effect of various risks compare to large organizations. According to European commission, SBA fact sheets more than $99.9 \%$ of overall registered enterprises in Turkey fall within the SMEs classification [1]. Since they have significant contribution in human capital and value-added creation, SMEs require the adoption of an effective risk management (RM) system.

The current study aims to see how RM is practicing by SMEs of different industrial sectors in Turkey. Regards the significance of SMEs in Turkish economy growth, the topic of this study is to see if there is any systematic RM process in Turkish SMEs and if RM practices show any dependency to industrial sectors.

Manuscript received February 20, 2017; revised April 7, 2017.

F. Soleimani Zoghi is with SRH University of Applied Sciences Berlin, Business Administration, Berlin, Germany (e-mail farzaneh.zoghi@srh-uni-berlin.de).

\section{THEORETICAL FRAME}

\section{A. The Definition of "Risk"}

Risk affects all aspects of business activities. Risk could be considered not only as a possible loss but also as a possible gain. However, Managers generally associate risk with negative outcomes [2]-[6]. A search of the RM literature reveals many definitions about risk [7]-[11]. ISO Guide 73:2009 which provides the definitions of generic terms related to RM and encourages a mutual and consistent understanding of the description of activities relating to the management of risk, defines risk as "the effect of uncertainty on objectives" [12]. The guide notes that objectivities can differ in terms of its diverse aspects (such as financial, health and safety, and environmental goals) and application levels (such as strategic, organization wide, project, product and process). In this concept, uncertainty arises from a lack of information or understanding associated with an event, consequence of an event or its likelihood. So, the term "uncertainty" refers to the unpredictability of environmental or organizational variables that impact corporate performance [13], [14] or the inadequacy of information about these variables [15], [16].

Risk can be divided into different types according to how its realization impacts on a business and its environment. Harland et al. summarizes and combines various authors' work to show different risk types including; Strategic risk, Operations risk, Supply risk, Customer risk, asset impairment risk, Competitive risk, Reputation risk, Financial, Fiscal and Regulatory risk, and Legal risk [11]. Clearly all types of risk need to be assessed and treated. However the priority for dealing with special type of risks could vary respect to size and sector of companies.

\section{B. Risk Management Process}

The management of risk is one of the most important issues facing organizations today. Having a process to identify major business risks in place is one of the crucial procedures of running an effective control system in companies. RM is not anymore only financial and insurable risks rather it is extending its focus on every operational and strategic level of organizations. Identification of key business risks in a timely manner, considering their likelihood, measuring significance of their financial impact on the business outcomes, establishing of priorities for allocating necessary resources and communicating results are among the most important criteria for assessing effectiveness on identification and evaluation of risks and control objectives [17].

Since every organization define and perceive risk in different way the process of RM could be described in 
different ways however its overall steps are generally close to each other. Generally speaking RM is a process in which risks should be identified, analyzed, assessed, managed and monitored. The extents to which risk process are actually applied vary respect to the size and industrial sector of company. Some organizations do only what is necessary to meet mandatory requirements and some organizations have not enough commitment to consider results of the risk process in current and future plans [17].

The tools and techniques of RM also are selected by organizations based on the type of business. It is important to note that there is no certain tool or technique for a particular type of risk. Who carries out risk assessment and general functions of RM process in organization and decision makers' attitude regards risk are among crucial factors that influence the effectiveness of RM within an organization [17].

\section{The Definition of SMEs}

According to European Commission, SMEs are defined as businesses which employ less than 250 staff and have an annual turnover of less than EUR 50 million, and /or their balance sheet total is less than EUR 43 million. They comprise three categories of enterprises, namely micro, small, and medium-sized enterprises [18]. The cabinet decree 2012/3834 issued in Official Gazette determined Micro, Small, Medium-sized enterprise definitions to group and categorize SMEs in Turkey parallel to the EU recommendation as well [19]. To belong to one of these categories, a firm must fulfill the following conditions:

Micro: The number of employee up to 9 and the limit for annual turnover and balance sheet up to EUR 1 million or 1 million Turkish Lira (TL)

Small: The number of employee from 10 to 49 and the limit for annual turnover and balance sheet from EUR 1 to 5 million or 8 million TL

Medium-sized: The number of employee from 50 to 249 and the limit for annual turnover and balance sheet from EUR 5 to 25 million or 40 million TL

The degree of independence is one of the criteria for being accepted as SME in Turkey; it means not more than $25 \%$ of capital and shares of a company should belong to one capital group [20]. The company structure of SMEs reveals special characteristics which also should be considered. The owner is present in the enterprise as an entrepreneur. He is liable for all decisions, so that his entrepreneurial risk is linked with the loss of wealth. Therefore, the owner has a personal and professional interest in all procedures and decisions involving the company. SMEs can reach a size and complexity that owner decide to delegate decision making authority to his employees [21].

Overall, there were positive trends in the number of SMEs during the period 2008-2012. Employment in SMEs exhibited large growth in Turkey as much as $20 \%$. The growth in value added in Turkey was as much as $15 \%$ during the period of 2008-2012 [18].

\section{Methodology AND DATA ANALYSIS}

\section{A. Research Objectives and Methodology}

The research topic is to determine the dependency of industrial sector of SMEs and their RM approach. The aim of study is to measure how often all risks which jeopardizing the company are identified and assessed, which risks are systematically is monitoring, which RM techniques are utilizing, who defines risk and risk limits in the company, are there documents that establish RM procedures in the company, is the company obligated to employ a RM system (If yes for which reasons) and does the company make experiences with certain clients or businesses available for colleagues (If yes in which ways). All together the current study aim to see how RM is practicing by SMEs of different sector in Turkey.

The sample was developed from the data of chamber of commerce and industry in Turkey. A database of 2000 data has been prepared based on three criteria: The most important industrial areas in Turkey (including Istanbul, Ankara, Izmir, Kayseri, Mersin, Adana, Konya, Gaziantep, Balikesir and Malatya), industrial sectors (including Construction, Capital goods, IT, Auditing/Consulting/ Training and Trade/ Logistics) and SMEs definition and classification. Cluster sampling technique has been selected and data has been collected through a structured interview by managers of 200 companies via phone, internet or face to face meeting. From 200 total responses 192 of them has been found as qualified response for statistical analysis. In current study response rate is $10 \%$. The average response rate of empirical studies on RM practices of SMEs varies from $8 \%$ to $17 \%$ [18].

Majority of participants are male $(78.9 \%)$, females are $17.9 \%$ of all participants and the rest $(3.2 \%)$ is unknown due to missing data. More than half of respondents $(62.1 \%)$ are aged between 30 and $45.50 \%$ of the participants are managing director or member of management team, $22.7 \%$ of the participants have a management role in financing and $22.7 \%$ of them work as a manager in sales department. Surprisingly among all SMEs there is less than $1 \%$ of participants that has a role as risk manager and head/member of inspection committee. It is quite clear that among total participants, corporate entity- i.e. Stock Corporation or limited liability company- is significantly dominated (89.5\%) as a legal form in the SMEs. Regards to the revenue and size of participant SMEs, more than half of the them (58.4\%) are Micro, $30.5 \%$ are Small, 6.8 are Medium and $4.2 \%$ are large. So, obviously the number of employees in micro and small SMEs is more than half of the total employee numbers (64.7\%). Participant companies are from five main industry sectors including; Construction (27.6\%), Capital goods (19.2\%), IT (8.9\%), Auditing/Consulting/Training (14.5\%) and Trade/Logistics (29.9\%).

Since data have been gathered by using categorical and multiple response questions with nominal and ordinal scales, Chi square test has been run for analyzing data. The results of Chi- square test have revealed evidence of relationship and association between variables in many cases.

\section{B. Data Analysis}

Firstly respondents have been asked which risks are systematically monitored in their company. Multiple response structure allows them to select more than one answer. Choices include None (N), Operational risks (OR), Strategic risks (SR), financial risks (FR), IT risks (ITR), Compliance risks (CR) and other kinds of risks (O). Cross-tabulation with 
respect of industrial sector (Table I) is applied to show frequencies.

\begin{tabular}{|c|c|c|c|c|c|c|c|}
\hline Sectors & $\mathrm{N}$ & OR & SR & FR & IT & $\mathrm{CR}$ & $\mathrm{O}$ \\
\hline Construction & $11.9 \%$ & $22.0 \%$ & $18.6 \%$ & $64.4 \%$ & $8.5 \%$ & $10.2 \%$ & $10.2 \%$ \\
\hline Capital goods & $22 . \%$ & $39 . \%$ & $17.1 \%$ & $43.9 \%$ & $24.4 \%$ & $9.8 \%$ & $7.3 \%$ \\
\hline IT & $5.3 \%$ & $36.8 \%$ & $21.1 \%$ & $68.4 \%$ & $31.6 \%$ & $21.1 \%$ & $5.3 \%$ \\
\hline Auditing/Consulting/Training & $9.7 \%$ & $38.7 \%$ & $16.1 \%$ & $58.1 \%$ & $6.5 \%$ & $19.4 \%$ & $19.4 \%$ \\
\hline Trade/Logistic & $10.9 \%$ & $34.4 \%$ & $31.3 \%$ & $68.8 \%$ & $7.8 \%$ & $10.9 \%$ & $4.7 \%$ \\
\hline
\end{tabular}

TABLE II: CROSS-TABULATION OF "SECTOR” AND "WHICH RISK MANAGEMENT TECHNIQUES ARE UTILIZED BY YOUR COMPANY?"

\begin{tabular}{|c|c|c|c|c|c|c|c|c|}
\hline Sectors & $\mathrm{Ex} / \mathrm{ES}$ & $\mathrm{In} / \mathrm{Su}$ & $\mathrm{BS} / \mathrm{SC} /$ & $\mathrm{Pr} / \mathrm{IM}$ & STM/STA & RMS & IA/IC & $\mathrm{N}$ \\
\hline Construction & $78.0 \%$ & $16.9 \%$ & $20.3 \%$ & $5.1 \%$ & $3.4 \%$ & $3.4 \%$ & $6.8 \%$ & $5.1 \%$ \\
\hline Capital goods & $61.0 \%$ & $24.4 \%$ & $31.7 \%$ & $4.9 \%$ & $7.3 \%$ & $2.4 \%$ & $26.8 \%$ & $14.6 \%$ \\
\hline IT & $68.4 \%$ & $42.1 \%$ & $21.1 \%$ & $5.3 \%$ & $5.3 \%$ & $5.3 \%$ & $42.1 \%$ & $0.0 \%$ \\
\hline Auditing/Consult/Train & $80.6 \%$ & $12.9 \%$ & $19.4 \%$ & $0.0 \%$ & $12.9 \%$ & $0.0 \%$ & $19.4 \%$ & $6.5 \%$ \\
\hline Trade/Logistic & $76.6 \%$ & $9.4 \%$ & $35.9 \%$ & $3.1 \%$ & $6.3 \%$ & $1.6 \%$ & $12.5 \%$ & $4.7 \%$ \\
\hline
\end{tabular}

TABLE III: CROSS- TABULATION OF “SECTOR” AND “WHO DEFINES RISK AND RISK LIMITS IN YOUR COMPANY?”

\begin{tabular}{|c|c|c|c|c|c|c|c|}
\hline Sectors & $\mathrm{MD} / \mathrm{MT}$ & FD & $\mathrm{CD}$ & IA & RMD & $\mathrm{EC}$ & $\mathrm{O}$ \\
\hline Construction & $94.9 \%$ & $22.0 \%$ & $1.7 \%$ & $5.1 \%$ & $1,7 \%$ & $3.4 \%$ & $0.0 \%$ \\
\hline Capital goods & $90.2 \%$ & $46.3 \%$ & $12.2 \%$ & $9.8 \%$ & $2.4 \%$ & $2.4 \%$ & $4.9 \%$ \\
\hline IT & $78.9 \%$ & $36.8 \%$ & $15.8 \%$ & $10.5 \%$ & $5.3 \%$ & $21.1 \%$ & $0.0 \%$ \\
\hline Auditing/Consulting/ Training & $93.1 \%$ & $27.6 \%$ & $3.4 \%$ & $10.3 \%$ & $0.0 \%$ & $6.9 \%$ & $3.4 \%$ \\
\hline Trade/Logistic & $92.1 \%$ & $34.9 \%$ & $4.8 \%$ & $3.2 \%$ & $1.6 \%$ & $1.6 \%$ & $3.2 \%$ \\
\hline
\end{tabular}

All SMEs from different industrial sectors systematically monitor financial risks mostly compare to the other types of risks $(68.8 \%$ of Trade/Logistic, $68.8 \%$ of IT, $64.4 \%$ of Construction, $58.1 \%$ of Auditing/Consulting/Training and $43.9 \%$ of Capital goods). In all industrial sectors Operational risks have been selected by respondents as the second type of risk that systematically are monitored in their company (39.0\% of Capital goods, 38.7\% of Auditing/Consulting/ Training, $36.8 \%$ of IT, $34.4 \%$ of Trade/Logistic and $22.0 \%$ of Consumption). However, the third type of risk that they systematically monitor differs in various industrial sectors. While in Construction and Trade/Logistics sectors strategic risk has been selected as the third type of risk $(18.6 \%, 31.3 \%)$, in Capital goods and IT sectors IT risks $(24.4 \%, 31.6 \%)$ and in Auditing/Consulting/ Training sector Compliance risks $(19.4 \%)$ have been selected as the third type of risks that systematically are monitored in their company.

The results of Chi-square test (chi-square value 58.784 and significance 0.007) and contingency tables show strong evidence of relation among two variables. In other words, type of risks that are systematically monitored by SMEs is dependent to their industrial sectors.

Secondly respondents have been asked which RM techniques are utilized by their company. Multiple response structure allows them to select more than one answer. Choices include Experience/ Estimation (Ex/ES), Interviews/Surveys (In/Su), Brian storming/Scenario analysis/ SWOT analysis (BS/SC), Probability/ Impact matrix (PR/IM), Stochastic modeling/statistical analysis (STM/STA), RM software (RMS), Internal auditor/ Internal consultant (IA/IC) and None (N). Cross-tabulation with respect of industrial sector (Table II) is applied to show frequencies.

All SMEs from different industrial sectors utilize Experience/ Estimation as main RM techniques in their company (80.6\% of Auditing/Consulting/Training, $78.0 \%$ of Construction, $76.6 \%$ of Trade/Logistic, $68.4 \%$ of IT, and
$61.0 \%$ of Capital goods). Except IT sector (Interviews/Surveys $42.1 \%$ and Internal auditor/ Internal consultant $42.1 \%$ ) the second technique that have been selected mostly by companies is Brian storming/Scenario analysis/ SWOT analysis $(20.35 \%$ of Construction, $31.7 \%$ of Capital goods, $19.4 \%$ of Auditing/Consulting/ Training and $35.9 \%$ of Trade/Logistic).

The results of Chi-square test (chi-square value 72.429 and significance 0.001 ) and contingency tables show very strong evidence of relation among two variables. In other words, RM techniques which are utilized by SMEs are dependent to their industrial sectors.

Thirdly respondents have been asked who defines risk and risk limits in their company. Multiple response structure allows them to select more than one answer. Choices include Managing director/ Member of management team (MD/MT), Financing Department (FD), Controlling Department (CD), Internal Auditing (IA), RM Department (RMD), External Consulting (EC) and Others (O). Cross-tabulation with respect of industrial sector (Table III) is applied to show frequencies.

Defining risk and risk limits in all SMEs from different industrial sectors mostly has been carried by Managing director/ Member of management team (94.9\% of Construction, $93.1 \%$ of Auditing/Consulting/ Training, 92.1\% of Trade/Logistic, $90.2 \%$ of Capital goods and $78.9 \%$ of IT). Again in all SMEs from different industrial sectors the second source for defining risk and risk limits is financing department (46.3\% of Capital goods, $36.8 \%$ of IT, $34.9 \%$ of Trade/Logistic, 27.6\% Auditing/Consulting/ Training and $22.0 \%$ Construction). The third one for Capital goods and Trade/Logistic $(12.2 \%, 4.8 \%)$ is controlling department while the third source for IT $(21.1 \%)$ is external consulting, for Construction and Auditing/Consulting/ Training is internal auditing $(5.1 \%, 10.3 \%)$.

The results of Chi-square test (chi-square value 31.470 and 
significance 0.393 ) and contingency tables show no evidence of relation among two variables. In other words, defining risk and risk limits in SMEs are not associated or is independent to their industrial sectors.

Next, respondents have been asked if there are documents that establish RM procedures in their company. Multiple response structure allows them to select more than one answer. Choices include RM handbook, Organizational rules, other written documents and None. Cross-tabulation with respect of industrial sector (Table IV) is applied to show frequencies.

TABLE IV: CROSS- TABULATION OF "SECTOR” AND “ARE THERE

\begin{tabular}{lllll} 
DoCUMENTS WHICH ESSTABILISH RM PROCEDURES IN YOUR COMPANY?" \\
\hline Sectors & $\begin{array}{l}\text { RM } \\
\text { Handbook }\end{array}$ & $\begin{array}{l}\text { Organizational } \\
\text { rules }\end{array}$ & $\begin{array}{l}\text { Other } \\
\text { written } \\
\text { documents }\end{array}$ & None \\
\hline Construction & $8.5 \%$ & $28.8 \%$ & $30.5 \%$ & $52.5 \%$ \\
Capital goods & $7.3 \%$ & $24.4 \%$ & $31.7 \%$ & $48.8 \%$ \\
IT & $10.5 \%$ & $36.8 \%$ & $47.4 \%$ & $36.8 \%$ \\
$\begin{array}{l}\text { Auditing/ } \\
\text { Consulting/ } \\
\text { Training } \\
\begin{array}{l}\text { Trade/ } \\
\text { Logistic }\end{array}\end{array}$ & $16.1 \%$ & $29.0 \%$ & $32.3 \%$ & $41.9 \%$ \\
\hline
\end{tabular}

SMEs from different industrial sectors mostly have no documents that establish RM procedures in their companies (56.3\% of Trade/Logistic, $52.5 \%$ of Construction, $48.8 \%$ of Capital goods, $41.9 \%$ of Auditing/Consulting/ Training and $36.8 \%$ of IT).

The results of Chi-square test (chi-square value 14.330 and significance 0.813 ) and contingency tables show no evidence of relation among two variables. In other words, having documents that establish RM procedures in SME company has been determined as independent of their industrial sectors.

Then, respondents have been asked if their company obligated to employ a RM system for some reasons. Multiple response structure allows them to select more than one answer Choices include Mandatory law (MR), General principles of proper business management (GP), Corporate governance code (CGC), ISO 31000 Standard (ISO), Access to credits (AC) and There are no requirements $(\mathrm{N})$. Cross-tabulation with respect of industrial sector (Table V) is applied to show frequencies.

TABLE V: CROSS- TABULATION OF "SECTOR" AND "IS YOUR COMPANY OBLIGATED TO EMPLOY A RISK MANAGEMENT SYSTEM FOR ONE OR MORE OF THE FOLLOWING REASONS?"

\begin{tabular}{lllllll}
\hline Sectors & MR & GP & CGC & ISO & AC & N \\
\hline Construction & $18.6 \%$ & $39.0 \%$ & $33.9 \%$ & $3.4 \%$ & $0.0 \%$ & $28.8 \%$ \\
Capital goods & $2.4 \%$ & $43.9 \%$ & $17.1 \%$ & $9.8 \%$ & $4.9 \%$ & $51.2 \%$ \\
IT & $26.3 \%$ & $68.4 \%$ & $26.3 \%$ & $5.3 \%$ & $5.3 \%$ & $5.3 \%$ \\
Auditing/ & $22.6 \%$ & $41.9 \%$ & $35.5 \%$ & $0.0 \%$ & $6.5 \%$ & $32.3 \%$ \\
$\begin{array}{l}\text { Consulting/ } \\
\text { Training }\end{array}$ & & & & & & \\
$\begin{array}{l}\text { Trade/ } \\
\text { Logistic }\end{array}$ & $14.1 \%$ & $50.0 \%$ & $21.9 \%$ & $3.1 \%$ & $3.1 \%$ & $45.3 \%$ \\
\hline
\end{tabular}

SMEs from all sectors mostly reported "General principles of proper business management" as obligatory requirement for RM $(68.4 \%$ of IT, $50.0 \%$ of Trade/Logistic, $43.9 \%$ of Capital goods, $41.9 \%$ of Auditing/Consulting/ Training and $39.0 \%$ of construction).
The results of Chi-square test (chi-square value 57.345 and significance 0.002 ) and contingency tables show very strong evidence of relation among industrial sector and mandatory law requirement for employing RM system in SMEs. In other words, obligation to employ a RM system is dependent to SMEs' industrial sectors.

Finally, respondents have been asked how often all risks jeopardizing their companies are identified and assessed. Choices include every three month $(3 \mathrm{M})$, every six month (6M), annually (An), sporadically (SP) and never (N). Cross-tabulation with respect of industrial sector (Table VI) is applied to show frequencies.

TABLE VI: CROSS- TABULATION OF "SECTOR” AND "HOW OFTEN THE RISKS JEOPARADIZING YOUR COMPANY ARE IDENTIFIED AND ASSESSED?"

\begin{tabular}{llllll}
\hline Sectors & $3 \mathrm{M}$ & $6 \mathrm{M}$ & $\mathrm{An}$ & $\mathrm{SP}$ & $\mathrm{N}$ \\
\hline Construction & $37.3 \%$ & $5.1 \%$ & $11.9 \%$ & $45.8 \%$ & $0.0 \%$ \\
Capital goods & $12.2 \%$ & $0.0 \%$ & $26.8 \%$ & $61.0 \%$ & $0.0 \%$ \\
IT & $28.6 \%$ & $9.5 \%$ & $9.5 \%$ & $52.4 \%$ & $0.0 \%$ \\
$\begin{array}{l}\text { Auditing/ } \\
\text { Consulting/ }\end{array}$ & $16.1 \%$ & $6.5 \%$ & $16.1 \%$ & $61.3 \%$ & $0.0 \%$ \\
$\begin{array}{l}\text { Training } \\
\text { Trade/ } \\
\text { Logistic }\end{array}$ & $35.4 \%$ & $3.1 \%$ & $18.5 \%$ & $43.1 \%$ & $0.0 \%$ \\
\hline
\end{tabular}

SMEs from different industrial sectors mostly reported that they identify and assess the risks that jeopardizing their company sporadically $(61.3 \%$ of Auditing/Consulting/ Training, $61.0 \%$ of Capital goods, $52.4 \%$ of IT, $45.8 \%$ of Construction and $43.1 \%$ of Trade/Logistic). The second option for Construction, IT and Trade/Logistic sector is every three month and for Capital goods and Auditing/Consulting/ Training sector is annually. None of the SMEs reported that they never identify and assess the risks that jeopardizing their company.

The results of Chi-square test (chi-square value 25.906 and significance 0.039 ) and contingency tables show evidence of relation among two variables. In other words, frequency of identifying and assessing risk is dependent to the industrial sector of SMEs.

\section{CONCLUSION}

The study reveals that Turkish SMEs are managing risks in a very basic level. In other words, a significant proportion of Turkish SMEs do not benefit from any guidelines in order to implement a RM system in their company. Moreover, SMEs from different industrial sectors mostly reported that they identify and assess risks that jeopardizing their company "Sporadically". Interestingly, in Capital goods sector, 22.0\% of participants reported that none of risk types was monitored systematically in their company and $14.6 \%$ of respondents in Capital goods sector reported that they use none of RM techniques in their companies. However IT is the only sector that utilizes any type of RM techniques. Since risk identification and risk assessment are vital components of an effective RM system it is inconceivable that Turkish SMEs have no regular system for identifying and assessing risks.

Approximately more than half of SMEs from Capital goods 
sector reported that there is no requirement for RM in their companies. Trade/Logistic sector followed by Auditing/Consulting/ Training and Construction sectors $(45.3 \%, 32.3 \%$ and $28.8 \%)$ reported the lack of obligatory requirements for RM too. Although, in Turkey, there are some requirements for RM and corporate governance by trade law, accounting law, banks (BASEL II) and ISO 31000 standard, it seems that most of SMEs simply do not consider any of them in their RM process.

Defining risk and risk limits in all SMEs from different industrial sectors mostly has been carried by Managing director/ Member of management team in Turkish SMEs. An investigation carried out by the IfM (Institute for Manufacturing) in 2001 indicated that in SMEs of macro and small size less than $25 \%$ of decisions were delegated. The lack of appropriate organizational culture, structure and management principle are main reasons that have been indicated. Moreover, Characteristics of decision makers such as demographic variables (including age, gender, nationality, education level) and personality (risk attitude) also affect RM practices in companies [22]. Anil and Cakir recently examined risk perception in Turkish SMEs. According to authors, Turkish managers perceive risk as loss and excitement based on their cultural differences. They observed that risk perception differ in construction and IT firms [23].

Considering SMEs crucial rule in Turkey's economic growth and their significant contribution in human capital and value-added creation, the results of present study reveal the necessity of an emergency plan in establishing a systematic $\mathrm{RM}$ process in SMEs.

\section{REFERENCES}

[1] European Commission. (2012 b). SBA fact sheets. [Online]. p. 1. Available:

http://ec.europa.eu/enterprise/policies/sme/facts-figures-analysis/perf ormance-review/files/countries-sheets/2012/turkey_en.pdf

[2] W. D. Rowe, "Risk assessment: approaches and methods," in Society, Technology and Risk Assessment, J. Conrad, Ed. London, Academic Press, 1980.

[3] J. G. March and Z. Shapira, "Managerial perspective on risk and risk taking," Management Science, vol. 33, pp. 1404-1418, 1987.

[4] J. F. Yates and E. R. Stone, "Risk appraisal," in Risk-Taking Behavior, J. F. Yates, Ed. Wiley, Chichester, 1992, pp. 49-85

[5] T. H. Chiles and J. F. McMackin, "Integrating variable risk preferences, trust and transaction cost economics," Academy of Management Review, vol. 21, no. 1, pp. 73-99, 1996.

[6] V. W. Mitchell, "Consumer perceived risk: Conceptualizations and models," European Journal of Marketing, vol. 33, no. 1/2, pp. 163-195, 1999.

[7] H. M. Markowitz, "Portfolio selection," Journal of Finance, vol. 7, no. 1, pp. 77-91, 1952.
[8] W. W. Lowrance, "The nature of risk," in How Safe is Safe Enough? R C. Schwing and W. A. Albers, Eds. Plenum Press, New York, NY, 1980 .

[9] K. Miller, "A framework for integrated risk management in international business," Journal of International Business Studies, vol. 23, no. 2, pp. 311-31, 1991.

[10] V. W. Mitchell, "Organisational risk perception and reduction: A literature review," British Journal of Management, vol. 6, pp. 115-133, 1995.

[11] C. Harland, R. Brenchley, and H. Walker, "Risk in supply networks," Journal of Purchasing and Supply Management, vol. 9, pp. 51-62, 2003.

[12] ISO Guide 73:2009. [Online]. Available: http://www.iso.org/iso/catalogue_detail?csnumber=44651

[13] R. E. Miles and C. C. Snow, Organizational Strategy, Structure, and Process, Stanford University Press, 2003.

[14] J. Pfeffer and G. R. Salancik, The External Control of Organizations: A Resource Dependence Perspective, New York: Harper and Row, 1978.

[15] R. B. Duncan, "Characteristics of organizational environments and perceived environmental uncertainty," Administrative Science Quarterly, vol. 17, no. 3, pp. 313-327, 1972.

[16] J. R. Galbraith, Organization Design, Addison-Wesley Publishing Company, 1977.

[17] T. Merna and F. F. Al-Thani, Corporate Risk Management, $2^{\text {nd }}$ Edition, John Wiley and Sons, 2008.

[18] Annual report on European SMEs 2014/2015. [Online]. Available: file://C:/Users/SRH\%20Berlin/Downloads/2015\%20SME\%20Annua 1\%20Report_final_12-11-15.pdf

[19] T. C. R. Gazete. (November 4, 2012). [Online]. Available: http://www.resmigazete.gov.tr/eskiler/2012/11/20121104-11.htm

[20] SMEs in Turkey. [Online]. Available: http://www.kobitek.com

[21] T. Henschel, Risk Management Practices of SMEs: Evaluating and Implementing Effective Risk Management Systems, Schmidt (Erich), Berlin: 2008.

[22] T. K. Das and B. Teng, "Relational risk and its personal correlates in strategic alliances," J. Bus. Psychol, vol. 15, pp. 445-461, 2001.

[23] I. Anil and O. Cakir, "Cultural differences and the effects on risk management practices: An empirical study in Turkish and Germany," in Proc. 5th Annual International Conference on Innovation and Entrepreneurship, Bildiriler Kitabı, Dec. 14-15, 2015.

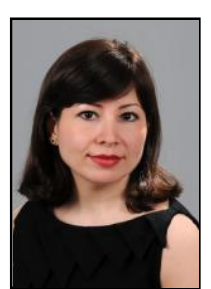

Farzaneh Soleimani Zoghi was borned in Iran in 1976 She completed her master degree at Tehran Azad University in the field of international marketing on 2008 and her Ph.D. at Marmara University in Istanbul in the field of production management and marketing on 2015. Her Ph.D. thesis is about relational risk management in strategic partnerships and her main research interest is business relationship management.

She participated in a joint project between SRH Hochschule Berlin and Marmara University for two years (2012-2014). The aim of project was to investigate cultural differences of practicing risk management between Germany and Turkey and providing recommendations on the basis of the research results.

Dr. Soleimani Zoghi is research associate in Contractual Management Institute (CMI) Berlin since 2014 and lecturer at SRH Hochschule Berlin since 2015. She lectures on Marketing Management, Leading and Managing Organizations and Human Resource Management for Bachler program and Research Methodology and Strategic Network Management for Master Seminars in International Business Administration program. 